
\title{
Birliktelik)
}

\section{Sarcoidosis and IgA Nephropathy: a Rare Association}

Cantürk Taşcı, ${ }^{1}$ Alper Gündoğan, ${ }^{1}$ Nesrin Çandır, ${ }^{1}$ illker Yılmaz, ${ }^{2}$ ïbrahim Yavan, ${ }^{3}$ Ömer Deniz, ${ }^{1}$ Ergun Tozkoparan,' Hayati Bilgiç

\section{Özet}

Sarkoidoz, yüz binde 0,1-640 prevalansı olan, sebebi net olarak bilinmeyen, tutulan organlarda nonkazeifiye granülomlarla kendini gösteren, sistemik kronik granülomatöz bir hastalıktır. Akciğer dışında cilt, göz, eklem tutulumları belirgindir. Böbrek tutulumunun \%0,9 oranında olduğunu gösteren çalışmalar mevcuttur. Olguların \%50'sinde kalsiyum metabolizması bozukluğu bulunmaktadır. Ancak proteinüri, hematüri gibi bulgular sarkoidozda beklenen komplikasyonlar arasında değildir. Takipleri sırasında belirgin proteinüri görülen ve yapılan böbrek biyopsisinde IgA nefropatisi saptanan sarkoidoz tanılı hastayı literatürler eşliğinde tartıştık.

Anahtar Sözcükler: Ig A, nefropati, sarkoidoz.

\begin{abstract}
Sarcoidosis a systemic chronic granulomatous disease characterized by noncaseating granulomas in the involvement organs. The etiology of the disease has yet to be precisely defined. The prevalence of sarcoidosis is 0.1-640 per one hundred thousand. In addition to the lungs, the other commonly involved organs are the skin, eyes, and joints. In previous investigations renal disorders were reported as $0.9 \%$ of sarcoidosis cases. In $50 \%$ of these cases, calcium metabolism disorders were found. However, proteinuria and hematuria are not common complications of sarcoidosis. This case report aims to argue for the rare association of sarcoidosis and IgA nephropathy, by presenting a case with proteinuria and $\lg A$ nephropathy in the renal biopsy.
\end{abstract}

Key words: Ig A, nephropathy, sarcoidosis.
'Gülhane Tıp Fakültesi Göğüs Hastalıkları Anabilim Dalı, Ankara

${ }^{2}$ Gülhane Tıp Fakültesi Nefroloji Bilim Dalı, Ankara

${ }^{3}$ Gülhane Tıp Fakültesi Patoloji Anabilim Dalı, Ankara
'Gülhane Medical Faculty, Department of Pulmonary Medicine, Ankara, Turkey

${ }^{2}$ Gülhane Medical Faculty, Department of Nephrology, Ankara, Turkey

${ }^{3}$ Gülhane Medical Faculty, Department of Pathology, Ankara, Turkey

Submitted (Başvuru tarihi): 15.09.2012 Accepted (Kabul tarihi): 05.11.2012

Correspondence (Iletişim): Cantürk Taşcı, Gülhane Tıp Fakültesi Göğüs Hastalıkları Ana Bilim Dalı, Ankara e-mail: ctasci@gata.edu.tr 
Sarkoidoz tutulan organda epiteloid hücre granülomları ile karakterize (nonkazeifiye granülomlar) kronik, sebebi bilinmeyen sistemik bir hastalıktır. Sarkoidozda renal hastalığın \%0,9 oranında olduğunu gösteren çalışmalar mevcut ise de klinik olarak önem taşıyan renal tutulumun sıklığı da oldukça azdır (1). Klinik olarak belirgin hastalık sıklığı düşük olsa da sarkoidozlu hastaların \%20 sinde histolojik olarak granülomatöz renal tutulum gösterilebilir (2). Sıklıkla renal hastalıktan hiperkalsemi ve hiperkalsüri sorumludur, ancak granülamatöz interstisyel nefrit, glomerüler hastalık, obstrüktif üropati ve nadiren son dönem böbrek hastalığı da görülebilir $(3,4)$.

Sarkoidozda renal hasar granülomlar ve aktive makrofajlar tarafından 1,25-dihidroksi vitamin D3 (kalsitriol)'ün anormal sentezlenmesi sonucu kalsiyum metabolizmasının bozulması; renal parankimin granülamatöz infiltrasyonunun sonuçları ve rastlantısal olduğu kadar sarkoidoz patogenezinde tetiklenen immün cevap ile ilişkili olan glomerüler hastalıklar ile oluşur (3).

Sarkoidozda glomerüler tutulum nadirdir. İzole vakalarda membranöz nefropati, IgA nefropatisi, Minimal Change hastalığı, proliferatif veya kresentrik glomerülonefrit ve fokal segmental glomerülosklerozu içeren çeşitli değişik lezyonlar tanımlanmıştır (5-8). Glomerüler hasarın hangi mekanizma ile oluştuğu bilinmediği gibi sarkoidoz ile olan ilişkisi de kanıtlanabilmiş değildir.

Sarkoidoz tanısı ile takip edilen olgumuzda ortaya çıkan hematüri ve proteinüri ile renal tutulum araştırılmış ve lgA nefropatisi tanısı konularak tedavi başlanmıştır.

\section{OLGU}

Boyundaki şişlik şikâyeti ile lenf nodu biyopsisi yapılan ve biyopsi sonucu kronik granülomatöz lenfadeni† gelen 21 yaşındaki erkek hasta, granülomatöz hastalıkların ayırıcı tanısı açısından kliniğimize başvurdu. Genel durumu iyi olan hastanın vital bulguları ise stabildi. PA akciğer grafisinde her iki hilus dolgun görünümdeydi (Şekil 1). Toraks bilgisayarlı tomografisinde (BT), her iki hiler bölge, prekarinal, subkarinal, sağ paratrakeal, sol aortikopulmoner pencere konglomere lenfadenopatiler vardı (Şekil 2). Olası sarkoid oz yönünden yapılan dermatolojik, oküler ve kardiak değerlendirmede patolojik bulguya rastlanmadı. Laboratuar tetkiklerinde serum kalsiyumu 10, 1 mg/dl, 24 saatlik idrar kalsiyumu 160 mg/gün olarak ölçüldü.

Fiberoptik bronkoskopi yapılan hastada sağ orta lob bronşu dıştan bası ile daralmışıı, üst lob intermediate lob ayrım karinası küntleşmiş olarak izlendi. Buralardan mukozal biyopsiler alındı.

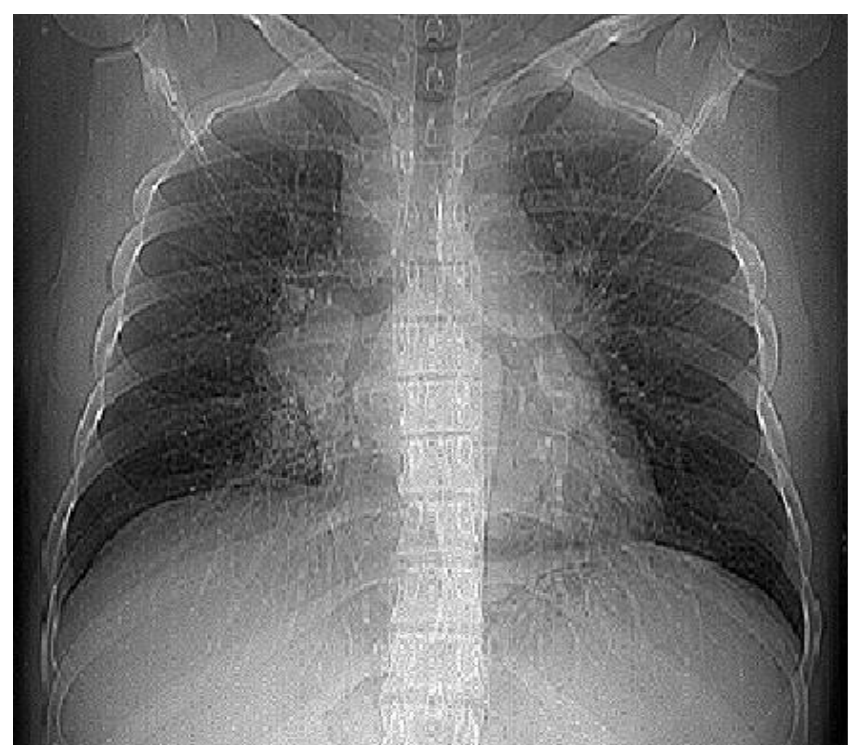

Şekil 1: Bilateral hiler dolgunluk.

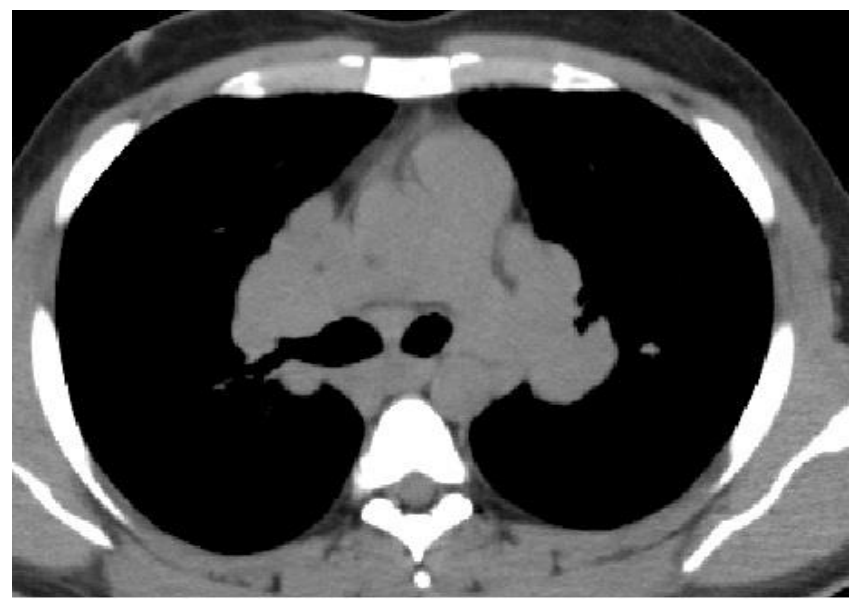

Şekil 2: Prekarinal, subkarinal, pretrakeal, prekaval bilateral patolojik boyutta lenfadenopatiler.

$\mathrm{BT}^{\prime}$ de görülen 7 no'lu lenf nodu istasyonuna ince iğne aspirasyon biyopsileri yapıldı. İnce iğne aspirasyon biyopsilerinde ve mukozal biyopsilerde granülamatöz inflamasyon izlendi (Şekil 3), aside dirençli basil izlenmedi. Bronkoalveoler lavaja ARB bakıldı ve negatif olarak geldi, kültüründe üreme olmadı. Solunum fonksiyon testlerinde FVC: \%89, FEV1: \%80, FEV1/FVC: \%83, DLCO: 86, DLCO/VA: 117 olarak ölçüldü. Hasta radyolojik olarak evre 1 sarkoidoz kabul edilerek tedavisiz takibe alındı. Semptomatik olmayan hasta beş ay tedavisiz olarak takip edildi.

Takibin beşinci ayında kontrol için başvuran hastanın çekilen akciğer grafisinde bilateral hiluslar dolgun, akciğer parenkiminde interstisyel patern belirgin olarak izlendi (Şekil 4). Toraks tomografisinde, önceki ile karşılaştırıldığında mediastinal lenfadenopatilerde anlamlı değişiklik izlenmedi. 


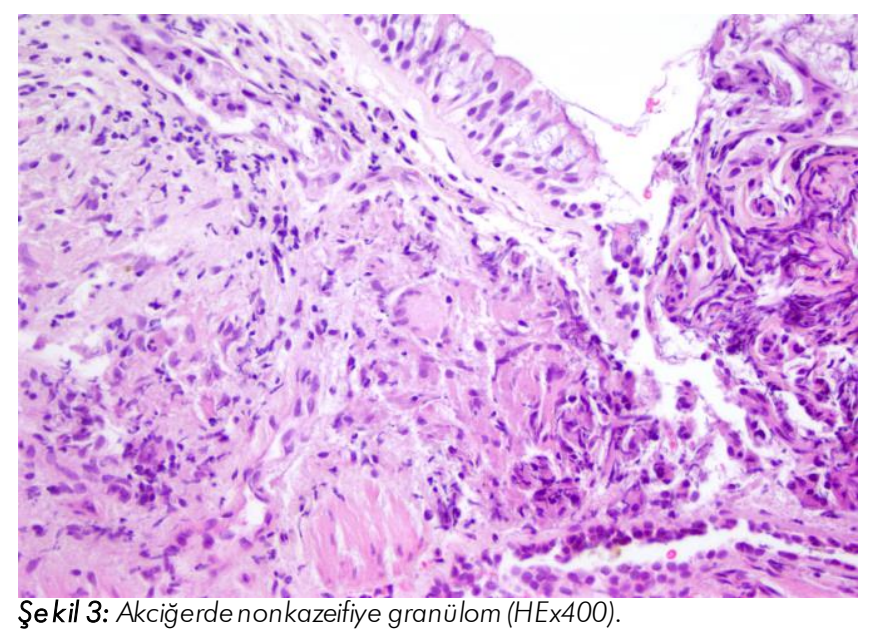

Solunum fonksiyon testleri, FVC: \%83, FEV1: \%73, FEVI/FVC: \%74, DLCO: 76, DLCO/VA: 114 olarak ölçüldü. Hastanın laboratuvar tetkiklerinde al bumin: 3,35 $\mathrm{g} / \mathrm{dL}$, tam idrar tetkikinde protein: ++, eritrosit: 25-30, lökosit: 2-3 olarak saptandı. Yapılan kontrol idrar tetkikinde tekrar protein: +++ saptanması üzerine, 24 saatlik idrar proteini ölçüldü. $1290 \mathrm{mg} / \mathrm{g}$ ün ve kontrolü 1630 $\mathrm{mg} / \mathrm{gün}$ olarak ölçüldü. ANA (-) negatif olan hastanın renal ultrasonografi'de parankim ekoları grade 1 ile uyumlu artmış olarak izlenmesi üzerine renal biyopsi yapıldı. Sol böbrek iğne biyopsisinde yarım ay oluşumu ile komplike olmuş diffüz proliferatif glomerülon efrit izlendi. İmmünofloresan incelemede glomerüllerde diffüz, global, mezengiyal ve paramezengiyal kaba granüller $(3+) \lg A$, $(2+)$ C3, $(2+)$ kappa hafif zincir ve $(1+) \lg M$ antikor birikimi saptandı. Histopatolojik ve immünofloresan bulgular IgA nefropatisi (Şekil 5a-b) ile uyumlu olarak değ erlendirildi.

Evre 2 sarkoidoz ve lgA nefropatisi birlikteliği olarak değerlendirilen hastaya nefroloji konsültasyonu ile birlikte $0,5 \mathrm{mg} / \mathrm{kg} / \mathrm{gün}$ dozunda prednizolon başlandı. Tedavisinin altıncı ayında olan hastanın 24 saatlik idrar proteini normal seviyelerdedir.

\section{TARTIŞMA}

Sarkoidoz değişen yaygınlıkta ve derecede olmak üzere tüm organları tutabilir $(9,10)$. Ekstrapulmoner sarkoidoz olarak adlandırılan bu tabloda en sık tutulan bölgeleri; deri, göz, retiküloendotelyal sistem, iskelet kas sistemi, ekzokrin bezler, kalp, böbrek ve santral sinir sistemi oluşturmaktadır.

Kalsiyum metabolizmasına bağlı görülen anormallikler sarkoidozda en sık karşılaşılan renal ve elektrolit bozukluklarını oluşturmaktadır. Kalsiyum metabolizmasındaki defekt aktive makrofajlar tarafından ekstrarenal kalsitriol üretimine bağlı olarak oluşmaktadır.

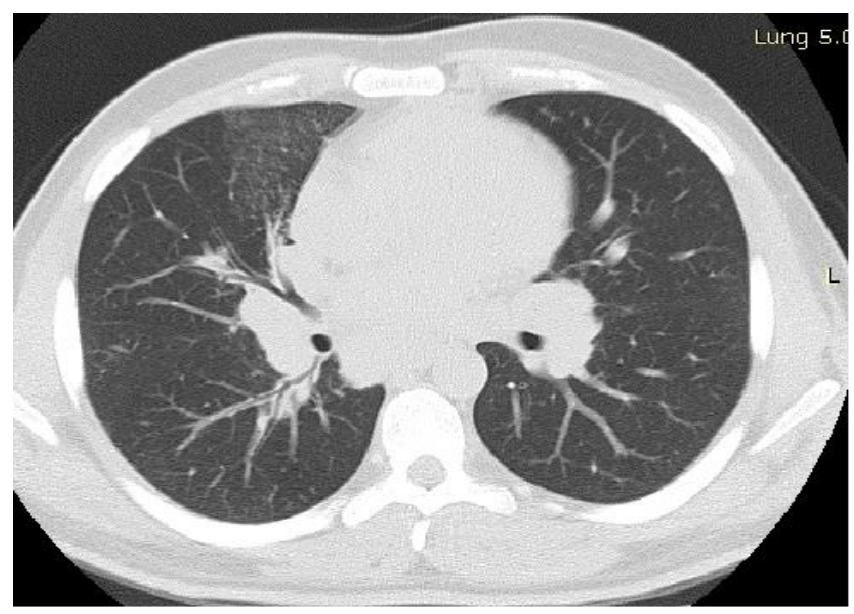

Şekil 4: Bilateral hiler lenfadenopative buzlu cam görünümü.

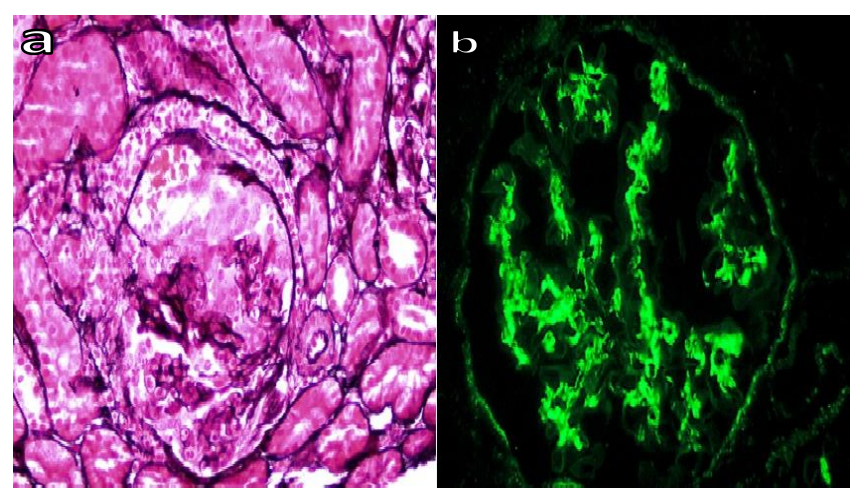

Şekil 5 a,b: Endokapiller proliferasyon gösteren ve sellüler yarım ay (kresent) içeren glomen̈l (a) (HEx400). Mezengial ve paramezengial alanlarda kaba granülerlg A birikimi (b) (immünofloresan x 400).

Sarkoidozda artmış intestinal kalsiyum emilimi, hiperkalsiüri (\%50'ye yakın), hiperkalsemi (\%10-20) ve nefrokalsinoza neden olabilir. Tedavi edilmezse renal kalsiyum depozisyonu kronik renal yetmezlik ve son dönem böbrek hastalığı ile sonuçlanabilir. Ancak hiperkalsiüri veya nefrokalsin ozis ol mayan hastalarda renal hasarın olmadığını varsaymak çok doğru olmaz. Sarkoidozda glomerüler tutulum nadir de olsa görülebilir. İzole vakalarda membranöz nefropati, IgA nefropatisi, Minimal Change hastalığı, proliferatif veya kresentrik glomerülonefrit ve fokal segmental glomerülosklerozu içeren çeşitli değişik lezyonlar tanımlanmıştır $(5,8)$. Ancak glomerüler hasarın hangi mekanizma ile oluştuğu bilinmediği gibi sarkoidoz ile olan ilişkisi de kanıtlanabilmiş değildir.

Berger ve Hinglias ilk kez 1968 yılında IgA nefropatisini tanımlamışlardır (11). IgA nefropatisi dünyada en sık görülen primer gromelüronefriti oluşturmaktadır. IgA nefropatisi ve sarkoidoz arasında bir ilişki olduğu ifade edilebilir, ancak oldukça tarıışmalıdır. Her ikisi de sebebi bilinmeyen sistemik bozukluklardır. Ailesel geçişler hem IgA nefropatisinde hem de sarkoidozda bildirilmiştir $(12,13)$. Tek bir gen sorumlu tutulamaz ancak HLA bağlantısı her iki hastalık içinde söz konusudur $(14,15)$. An- 
cak yine de ikisi arasındaki en güçlü bağlantı immünolojik yönden kurulabilir. Her iki hastalıkta da dolaşımda özellikle IgA kompleksleri başta olmak üzere dolaşan immünkomplekslerde bir artış söz konusudur $(16,17)$. Her iki hastalıkta da çoğunlukla benign bir seyir izlenir ve spontan remisyonlar gözlenir.

Tedavisiz olarak takiplerde olan bizim olgumuzda takibin beşinci ayında çekilen akciğer grafisinde parenkimde interstisyel patern belirgin olarak izlenmişti. Evre 2 sarkoidoz ola rak değerlendirilen hastanın, bir önceki kontrolüne göre evre 1'den 2'ye geçiş gösterdiği izlen miştir. Hastanın proteinürisi ve hematürisinin de yine bu dönemde karşımıza çıkması sarkoidozun progresyonu ile lgA nefropatisinin ortaya çıkışı arasında bir bağlantı olabileceğini akla getirmektedir.

Sarkoidoz ile IgA nefropatisi arasında bir ilişki olduğunu ileri süren literatürlerin sayısı gün geçtikçe artmakla birlikte $(18,19)$, varsa bu ilişkinin gösterilebilmesi için ileri bilimsel araştırmalara ihtiyaç duyulduğu açıktır. Bu süre zarfinda böyle bir ilişkinin var olabileceği sarkoidozlu hastalar takip edilirken göz önünde bulundurulmalıdır.

\section{ÇIKAR ÇATIŞMASI}

Bu makalede herhangi bir çıkar çatışması bildirilmemiş̧ir.

\section{KAYNAKLAR}

1. Okumuş G, Müsellim B, Çetinkaya E, Türker H, Uzaslan E, Yenturk $E$, et al. Extrapulmonary involvement in patients with sarcoidosis in Turkey. Respirology 2011 ; 16:446-50. [CrossRef]

2. Göbel U, Kettritz R, Schneider W, Luft F. The protean face of renal sarcoidosis. J Am Soc Nephrol 2001; 12:616-23.

3. Casella FJ, Allon M. The kidney in sarcoidosis. J Am Soc Nephrol 1993; 3:1555-62.

4. Muther RS, McCarron DA, Bennett WM. Renal manifestations of sarcoidosis. Arch Intern Med 1981; 141:643-5. [CrossRef

5. Goldszer RC, Galvanek EG, Lazarus JM. Glomerulonephritis in a patient with sarcoidosis. Report of a case and review of the literature. Arch Pathol Lab Med 1981; 105:478-81.

6. Jones B, Fowler J. Membranous nephropathy associated with sarcoidosis. Response to prednisolone. Nephron 1989; 52:101-2. [CrossRef]

7. Van Uum SH, Cooreman MP, Assmann KJ, Wetzels JF. A 58 -year-old man with sarcoidosis complicated by focal crescentic glomerulonephritis. Nephrol Dial Transplant 1997; 12:2703-7.

8. Dahl K, Canetta PA, D'Agati VD, Radhakrishnan J. A 56year-old woman with sarcoidosis and acute renal failure. Kidney Int 2008; 74:817-21. [CrossRef]

9. Baughman RP, Teirstein AS, Judson MA, Rossman MD, Yeager $\mathrm{H}$ Jr, Bresnitz EA, et al. Case Control Etiologic Study of Sarcoidosis (ACCESS) research group, Clinical characteristics of patients in a case control study of sarcoidosis. Am J Respir Crit Care Med 2001; 164(10 Pt 1): $1885-9$.

10. Cozier YC, Berman JS, Palmer JR, Boggs DA, Serlin DM, Rosenberg L. Sarcoidosis in black women in the United States: data from the Black Women's Health Study. Chest 2011; 139:144-50. [CrossRef]

11. Berger J, Hinglias N. [Intercapillary deposits of lgA-lgG]. [Article in French] J Urol Nephrol 1968; 74:694-5.

12. Hsu SI, Ramirez SB, Winn MP, Bonventre VJ, Owen WE. Evidence for genetic factors in the development and progression of IgA ne phropathy. Kidney Int 2000; 57:181835. [CrossRef

13. Harrington DW, Major M, Rybicki B, Popovich J, Maliarik M, lannuzzi MC. Familial sarcoidosis: analysis of 91 families. Sarcoidosis. 1994; 11:240-3.

14. Pasturenzi L, Martinetti M, Cuccia M, Cipriani A, Semenzato G, Luisetti M. HLA class I, II, and III polymorphism in Italian patients with sarcoidosis: The Pavia-Padova Sarcoidosis Study Group. Chest 1993; 104:1170-5. [CrossRef]

15. Gardner J, Kennedy HG, Hamblin A, Jones E. HLA associations in sarcoidosis: a study of two ethnic groups. Thorax 1984; 39:19-22. [CrossRef]

16. Donadio JV, Grande JP. Immuno globulin A nephropathy: a clinical perspective. J Am Soc Nephrol 1997; 8:132432.

17. Semenzato G. Immunology of interstitial lung diseases: cellular events taking place in the lung of sarcoidosis, hypersensitivity pneumonitis and HIV infection. Eur Respir J 1991 ; 4:94-102.

18. Khan A, Hodges N, Lord M. A Case of Sarcoidosis in a patient with IgA nephropathy. MedGenMed 2005; 7: 7.

19. Nishiya $H$, Yoshida H, Tomonari H, Hikita M, Shike T, Takeda $Y$, et al. Sarcoidosis representing multiple splenic nodules in a patient with $\lg A$ nephropathy. [Article in Japanese] Nihon Jinzo Gakkai Shi 1996; 38:40-5. 